\title{
Algoritma Naïve Bayes Dalam Memprediksi Kepuasan Nasabah
}

\author{
Mhd. Gading Sadewo', Agus Perdana Windarto² ${ }^{2}$ Irfan Sudahri Damanik ${ }^{3}$ \\ 1,2,3STIKOM Tunas Bangsa Pematangsiantar \\ 1,2,3Pematangsiantar \\ Gading.sadewooo@gmail.com¹, agus.perdana@amiktunasbangsa.ac.id², irfansudahri@gmail.com³
}

\begin{abstract}
Customer satisfaction is very important in assessing the level of management and services provided by the bank. The purpose of this study is to predict customer satisfaction with the service quality of Bank BTN Pematangsiantar Branch in terms of Tangible, Reliability, Assurance, and Responsiveness. The sample of this study is the customer of Bank BTN Pematangsiantar Branch. Using the Naive Bayes algorithm, the author tries to predict customer satisfaction with the service quality of the bank. After manual calculations, verification is performed using RapidMiner software and a rule model is obtained. From the analysis process, it can be seen that the Naive Bayes algorithm can be implemented in predicting customer satisfaction with the service quality of the Bank. The testing carried out with RapidMiner software equipped with apply model and \% Performance, and accuracy of $88 \%$ is obtained.
\end{abstract}

Keywords: Data Mining, Customer, Nä̈ve Bayes

Abstrak - Kepuasan nasabah merupakan hal yang sangat penting dalam menilai tingkat manajemen dan pelayanan yang diberikan oleh pihak bank. Tujuan penelitian ini adalah untuk memprediksi kepuasan nasabah terhadap kualitas pelayanan Bank BTN Cabang Pematangsiantar yang ditinjau dari aspek Tangible (Bukti Nyata), Reliability (Keandalan), Assurance (Jaminan), Responsiveness (Ketanggapan). Sampel penelitian ini adalah nasabah Bank BTN Cabang Pematangsiantar. Menggunakan algoritma Nä̈ve Bayes, penulis mencoba memprediksi kepuasan nasabah terhadap kualitas pelayanan bank. Setelah perhitungan secara manual, maka dilakukan pembuktian dengan menggunakan software RapidMiner dan didapat sebuah model aturan (rule). Dari proses analisis, dapat diketahui bahwa algoritma Naïve Bayes dapat diimplementasikan dalam memprediksi kepuasan nasabah terhadap kualitas pelayanan pada Bank BTN Cabang Pematangsiantar. Pengujian yang dilakukan dengan software RapidMiner yang dilengkapi apply model dan \%Performance dan diperoleh accuracy sebesar $88 \%$.

Kata Kunci : Data Mining, Nasabah, Nä̈ve Bayes.

\section{PENDAHULUAN}

Berdasarkan Undang Undang RI Nomor 10 Tahun 1998 tentang Perbankan (pasal 1 dan 2) mengatakan bahwa bank merupakan suatu badan usaha yang menghimpun dana dari masyarakat dalam bentuk simpanan dan menyalurkannya dalam bentuk kredit dan atau bentuk-bentuk lain dengan tujuan untuk meningkatkan taraf hidup orang banyak. Bank juga dikenal dengan pelayanannya yang mengedepankan kepuasan nasabah demi memperoleh kepercayaan dari masyarakat sebagai nasabahnya. Kualitas pelayanan menjadi komponen utama bagi nasabah karena produk-produk utama bank merupakan suatu penawaran yang tidak berbeda dan pelayanan bank juga mudah ditiru. Oleh karena itu 
persaingan akan sangat dipengaruhi oleh kemampuan bank dalam memberikan pelayanan terbaik dan bermutu dibandingkan pesaingnya, khususnya pada bagian frontliner. Frontliner merupakan sebuah kategori pekerjaan dalam suatu perusahaan yang bertugas untuk melayani customer secara langsung. Tugas frontliner di dunia perbankan secara umum memberikan informasi tentang produk-produk bank dengan jelas dan lengkap kepada nasabah. Fungsi frontliner menjadi garda depan dari suatu perbankan yang bersentuhan langsung dengan nasabah maupum calon nasabah, oleh karena itu diharapkan selalu memberikan kesan yang menarik setiap waktu. Adapun jabatan bagian frontliner meliputi: CS atau customer service, teller service, security [1]. Kepuasan nasabah merupakan aspek yang utama untuk mempertahankan reputasi perusahaan di mata masyarakat luas. Apabila nasabah merasa tidak puas dan kehilangan rasa percaya mereka, tidak menutup kemungkinan terjadinya penarikan dana secara besarbesaran (rush money) yang sangat membahayakan dan berdampak bank mengalami krisis keuangan dan gejolak ekonomi, sehingga sangat perlu ditingkatkan mengingat peranan nasabah sangat besar dalam kontribusi pendapatan secara langsung maupun tidak langsung guna menjaga eksistensi perusahaan. Dalam penelitian ini dibahas pengaruh kualitas pelayanan frontliner terhadap kepuasan nasabah bank. Di dalam ilmu komputer banyak cabang ilmu dan metode yang terdapat didalamnya seperti Sistem Pendukung Keputusan, Sistem Pakar, Data Mining dan lain-lain. Data mining adalah proses yang memperkerjakan satu atau lebih teknik pembelajran Komputer (mechine learning) untuk menganalisis dan mengekstraksi pengetahuan (knowledge) secara otomatis[2].

Algoritma Naive Bayes merupakan salah satu algoritma yang terdapat pada teknik klasifikasi. Naive Bayes merupakan pengklasifikasian dengan metode probabilitas dan statistik yang dikemukan oleh ilmuwan Inggris Thomas Bayes, yaitu memprediksi peluang di masa depan berdasarkan pengalaman dimasa sebelumnya sehingga dikenal sebagai Teorema Bayes. Teorema tersebut dikombinasikan dengan Naive dimana diasumsikan kondisi antar atribut saling bebas. Klasifikasi Naive Bayes diasumsikan bahwa ada atau tidak ciri tertentu dari sebuah kelas tidak ada hubungannya dengan ciri dari kelas lainnya[3]. Banyak penelitian terdahulu yang dilakukan dalam melakukan prediksi dengan menggunakan datamining algoritma Naïve Bayes dalam menyelesaikan masalah seperti yang dilakukan oleh [4] dan [5]. Diharapkan penelitian ini dapat menjadi masukan kepada Bank BTN KC Pematangsiantar dalam meningkatkan kualitas pelayanan terhadap nasabah.

\section{METODOLOGI PENELITIAN}

\subsection{Data Mining}

Data mining adalah proses yang memperkerjakan satu atau lebih teknik pembelajran komputer (mechine learning) untuk menganalisis dan mengekstraksi pengetahuan (knowledge) secara otomatis [2]. Data Mining bertujuan untuk memanfaatkan data dalam database dengan mengolah data tersebut sehingga menghasilkan informasi baru yang berguna untuk kepentingan perusahaan atau instansi [6]-[11]. 


\subsection{Klasifikasi}

Klasifikasi merupakan proses untuk menemukan model atau fungsi yang menjelaskan atau membedakan konsep atau kelas data, dengan tujuan untuk dapat memperkirakan kelas dari suatu objek yang labelnya tidak diketahui. Dalam mencapai tujuan tersebut, proses klasifikasi membentuk suatu model yang mampu membedakan data kedalam kelas-kelas yang berbeda berdasarkan aturan atau fungsi tertentu. Model itu sendiri bisa berupa aturan "jika-maka", berupa pohon keputusan, atau formula matematis[3].

\subsection{Naïve Bayes}

Naive Bayes merupakan sebuah pengklasifikasian probabilistik sederhana yang menghitung sekumpulan probabilitas dengan menjumlahkan frekuensi dan kombinasi nilai dari dataset yang diberikan. Naive Bayes yang dikemukakan oleh ilmuan inggris Thomas Bayes, yaitu memprediksi peluang di masa depan berdasarkan pengalaman di masa sebelumnya. Keuntungan penggunaan Naive Bayes adalah bahwa metode ini hanya membutuhkan jumlah data pelatihan (Training Data) yang kecil untuk menentukan estimasi parameter yang diperlukan dalam proses pengklasifikasian[12]. Untuk menyelesaikan metode Naive Bayes dapat dilakukan dengan persamaan-persamaan sebagai berikut:

$\mathrm{P}(\mathrm{H} \mid \mathrm{X})=\left(\mathrm{P}(\mathrm{X} \mid \mathrm{H})^{*}(\mathrm{P}(\mathrm{H})) /(\mathrm{P}(\mathrm{X}))\right.$

Dimana:

$\mathrm{X} \quad$ : Data dengan class yang belum diketahui

$\mathrm{H} \quad$ : Hipotesis data merupakan suatu class spesifik

$\mathrm{P}(\mathrm{H} \mid \mathrm{X})$ : Probabilitas hipotesis $\mathrm{H}$ berdasarkan kondisi $\mathrm{X}$ (posteriori probabilitas)

$\mathrm{P}(\mathrm{H})$ : Probabilitas hipotesis $\mathrm{H}$ (prior probabilitas)

$\mathrm{P}(\mathrm{X} \mid \mathrm{H})$ : Probabilitas $\mathrm{X}$ berdasarkan kondisi pada hipotesis $\mathrm{H}$

$\mathrm{P}(\mathrm{X}) \quad$ : Probabilitas $\mathrm{X}$

\subsection{Teknik Pengumpulan Data}

Pengumpulan data dapat dilakukan dalam berbagai setting, berbagai sumber dan berbagai cara. Bila dilihat dari sumber datanya, maka pengumpulan data dapat menggunakan sumber primer dan sekunder. Sumber primer adalah sumber data yang langsung memberikan data kepada pengumpul data, dan sumber sekunder merupakan sumber yang tidak langsung memberikan data pada pengumpul data, misalnya lewat orang lain atau lewat dokumen. Selanjutnya kalau dilihat dari segi cara atau teknik pengumpulan data, maka teknik pengumpulan data dapat dilakukan dengan interview, kuesioner (angket), observasi. Untuk memperoleh data dalam penelitian ini, penulis menyebarkan kuesioner (angket) kepada nasabah Bank BTN KC Pematangsiantar, adapun jumlah kuesioner (angket) yang disebar sebanyak 50 .

\subsection{Teknik Pengolahan Data}

Data yang digunakan dalam penelitian ini berupa data primer. Dimana, data tersebut diperoleh dari hasil kuisioner yang disebarkan kepada nasabah Bank BTN 
KC Pematangsiantar. Sampel yang digunakan adalah 50 nasabah. Setelah data yang diperlukan diperoleh, kemudian ditentukan variabel-variabel yang akan digunakan dalam penelitian. Variabel independen yang digunakan antara lain Tangible (Bukti Nyata), Reliability (Keandalan), Assurance (Jaminan), Responsiveness (Ketanggapan). Sedangkan variabel responnya adalah kepuasan, yaitu nasabah yang puas dan tidak puas terhadap pelayanan bank. Kemudian data akan diuji menggunakan software RapidMiner untuk membuktikan hasil perhitungan manual adalah sama dengan system.

\section{HASIL DAN PEMBAHASAN}

\subsection{Proses Perhitungan}

Proses perhitungan untuk memprediksi kepuasan nasabah terhadap pelayanan Bank BTN KC Pematangsiantar menggunakan algoritma naïve bayes adalah sebagai berikut:

1. Menghitung Jumlah Class/Label

Jumlah data yang digunakan sebanyak 25 data, data Puas sebanyak 20 data dan data Tidak Puas sebanyak 5 data. Sehingga untuk menghitungn nilai probabilitasnya adalah sebagai berikut :

$$
\begin{aligned}
& \mathrm{P}(\text { Puas })=20 / 25 \\
& \mathrm{P}(\text { Puas })=0,8 \\
& \mathrm{P}(\text { Tidak Puas })=5 / 25 \\
& \mathrm{P}(\text { Tidak Puas })=0,2
\end{aligned}
$$

\begin{tabular}{|c|c|c|c|c|c|c|c|c|}
\hline Alt & A & B & C & D & $\mathbf{E}$ & $\mathbf{F}$ & G & Tanggapan \\
\hline A1 & Remaja & Pelajar & $\mathrm{L}$ & SB & SB & SB & SB & Puas \\
\hline A2 & Dewasa & PNS & $\mathrm{L}$ & B & B & $\mathrm{B}$ & B & Puas \\
\hline A3 & Remaja & Pelajar & $\mathrm{BR}$ & B & B & B & B & Puas \\
\hline A4 & Remaja & Pelajar & $\mathrm{CL}$ & B & SB & B & SB & Puas \\
\hline A5 & Tua & PNS & $\mathrm{L}$ & B & B & B & B & Puas \\
\hline $\mathrm{A} 6$ & Dewasa & Peg Swasta & $\mathrm{L}$ & $\mathrm{B}$ & $\mathrm{B}$ & $\mathrm{C}$ & $\mathrm{C}$ & Tidak Puas \\
\hline A7 & Dewasa & PNS & $\mathrm{L}$ & SB & SB & B & $\mathrm{C}$ & Puas \\
\hline A8 & Dewasa & PNS & $\mathrm{L}$ & $\mathrm{C}$ & $\mathrm{B}$ & $\mathrm{C}$ & $\mathrm{C}$ & Tidak Puas \\
\hline A9 & Remaja & Pelajar & $\mathrm{BR}$ & B & $\mathrm{C}$ & SB & B & Puas \\
\hline $\mathrm{A} 10$ & Remaja & Pelajar & $\mathrm{BR}$ & $\mathrm{B}$ & $\mathrm{C}$ & SB & $\mathrm{B}$ & Puas \\
\hline A11 & Remaja & Pelajar & $\mathrm{BR}$ & B & $\mathrm{C}$ & B & B & Puas \\
\hline A12 & Dewasa & Peg BUMN & CL & B & B & $\mathrm{C}$ & $\mathrm{C}$ & Puas \\
\hline A13 & Tua & Peg BUMN & CL & B & B & B & $\mathrm{C}$ & Puas \\
\hline A14 & Tua & PegBUMN & CL & B & B & B & $\mathrm{C}$ & Puas \\
\hline A15 & Dewasa & PNS & $\mathrm{CL}$ & B & B & B & SB & Puas \\
\hline A16 & Dewasa & PNS & $\mathrm{CL}$ & B & B & B & SB & Puas \\
\hline A17 & Dewasa & PNS & $\mathrm{L}$ & B & B & $\mathrm{C}$ & SB & Puas \\
\hline A18 & Tua & Wiraswasta & $\mathrm{L}$ & B & B & B & $\mathrm{C}$ & Puas \\
\hline A19 & Tua & Wiraswasta & $\mathrm{L}$ & B & $\mathrm{C}$ & $\mathrm{C}$ & $\mathrm{C}$ & Tidak Puas \\
\hline A20 & Tua & Wiraswasta & $\mathrm{L}$ & B & B & $\mathrm{C}$ & $\mathrm{C}$ & Tidak Puas \\
\hline A21 & Tua & PNS & BR & $\mathrm{C}$ & B & B & $\mathrm{C}$ & Puas \\
\hline A22 & Tua & PNS & $\mathrm{L}$ & B & SB & SB & B & Puas \\
\hline A23 & Dewasa & Wiraswasta & $\mathrm{L}$ & B & SB & SB & B & Puas \\
\hline A24 & Tua & Wiraswasta & $\mathrm{L}$ & B & SB & B & B & Puas \\
\hline A25 & Dewasa & Wiraswasta & $\mathrm{L}$ & B & $\mathrm{C}$ & $\mathrm{C}$ & $\mathrm{C}$ & Tidak Puas \\
\hline
\end{tabular}

Tabel 1. Data Training 
Keterangan :

A: Usia

B: Pekerjaan

C: Lama Menjadi Nasabah

D: Tangible

E: Reliability

F: Assurance

$\mathrm{G}:$ Responsiveness

2. Menghitung Jumlah Kasus Yang Sama Dengan Class Yang Sama

Setelah mencari nilai probabilitas setiap kriteria, didapatkan dari data training maka nilai probabilitas untuk masing-masing kriteria, dapat dilihat pada tabel berikut.

Tabel 2. Tabel Nilai Probabilitas Usia

\begin{tabular}{|l|c|c|c|c|}
\hline \multirow{2}{*}{ Usia } & \multicolumn{2}{|c|}{ Tanggapan } & \multicolumn{2}{c|}{ Probabilitas } \\
\cline { 2 - 5 } & Puas & Tidak Puas & Puas & Tidak Puas \\
\hline Remaja & 6 & 0 & 0.30 & 0 \\
\hline Dewasa & 7 & 3 & 0.35 & 0.6 \\
\hline Tua & 7 & 2 & 0.35 & 0.4 \\
\hline Jumlah & 20 & 5 & 1 & 1 \\
\hline
\end{tabular}

Tabel 3. Tabel Nilai Probabilitas Pekerjaan

\begin{tabular}{|l|c|c|l|c|}
\hline \multirow{2}{*}{\multicolumn{1}{|c|}{ Pekerjaan }} & \multicolumn{2}{c|}{ Tanggapan } & \multicolumn{2}{c|}{ Probabilitas } \\
\cline { 2 - 5 } & Puas & Tidak Puas & Puas & Tidak Puas \\
\hline Pelajar & 6 & 0 & 0.3 & 0 \\
\hline PNS & 8 & 1 & 0.4 & 0.2 \\
\hline Pegawai Swasta & 0 & 1 & 0 & 0.2 \\
\hline Pegawai BUMN & 3 & 0 & 0.15 & 0 \\
\hline Wiraswasta & 3 & 3 & 0.15 & 0.6 \\
\hline Jumlah & 20 & 5 & 1 & 1 \\
\hline
\end{tabular}

Tabel 4. Tabel Nilai Probabilitas Lama Menjadi Nasabah

\begin{tabular}{|c|c|c|l|c|}
\hline Lama Menjadi Nasabah & \multicolumn{2}{|c|}{ Tanggapan } & \multicolumn{2}{c|}{ Probabilitas } \\
\cline { 2 - 5 } & Puas & Tidak Puas & Puas & Tidak Puas \\
\hline B & 5 & 0 & 0.25 & 0 \\
\hline CL & 6 & 0 & 0.3 & 0 \\
\hline L & 9 & 5 & 0.45 & 1 \\
\hline Jumlah & 20 & 5 & 1 & 1 \\
\hline
\end{tabular}

Tabel 5. Tabel Nilai Probabilitas Tangible

\begin{tabular}{|c|r|c|l|c|}
\hline \multirow{2}{*}{ Tangible } & \multicolumn{2}{|c|}{ Tanggapan } & \multicolumn{2}{c|}{ Probabilitas } \\
\cline { 2 - 5 } & Puas & Tidak Puas & Puas & Tidak Puas \\
\hline SB & 2 & 0 & 0.1 & 0 \\
\hline B & 17 & 4 & 0.85 & 0.8 \\
\hline C & 1 & 1 & 0.05 & 0.2 \\
\hline K & 0 & 0 & 0 & 0 \\
\hline Jumlah & 20 & 5 & 1 & 1 \\
\hline
\end{tabular}


Tabel 6. Tabel Nilai Probabilitas Reliability

\begin{tabular}{|c|r|c|l|c|}
\hline \multirow{2}{*}{ Reliability } & \multicolumn{2}{|c|}{ Tanggapan } & \multicolumn{2}{c|}{ Probabilitas } \\
\cline { 2 - 5 } & Puas & Tidak Puas & Puas & Tidak Puas \\
\hline SB & 6 & 0 & 0.3 & 0 \\
\hline B & 11 & 3 & 0.55 & 0.6 \\
\hline C & 3 & 2 & 0.15 & 0.4 \\
\hline K & 0 & 0 & 0 & 0 \\
\hline Jumlah & 20 & 5 & 1 & 1 \\
\hline
\end{tabular}

Tabel 7. Tabel Nilai Probabilitas Assurance

\begin{tabular}{|c|r|c|l|c|}
\hline \multirow{2}{*}{ Assurance } & \multicolumn{2}{|c|}{ Tanggapan } & \multicolumn{2}{c|}{ Probabilitas } \\
\cline { 2 - 5 } & Puas & Tidak Puas & \multicolumn{1}{c|}{ Puas } & Tidak Puas \\
\hline SB & 5 & 0 & 0.25 & 0 \\
\hline B & 13 & 0 & 0.65 & 0 \\
\hline C & 2 & 5 & 0.1 & 1 \\
\hline K & 0 & 0 & 0 & 0 \\
\hline Jumlah & 20 & 5 & 1 & 1 \\
\hline
\end{tabular}

Tabel 8. Tabel Nilai Probabilitas Responsiveness

\begin{tabular}{|c|c|c|l|c|}
\hline \multirow{2}{*}{ Responsiveness } & \multicolumn{2}{|c|}{ Tanggapan } & \multicolumn{2}{c|}{ Probabilitas } \\
\cline { 2 - 5 } & Puas & Tidak Puas & Puas & Tidak Puas \\
\hline SB & 5 & 0 & 0.25 & 0 \\
\hline B & 9 & 0 & 0.45 & 0 \\
\hline C & 6 & 5 & 0.3 & 1 \\
\hline K & 0 & 0 & 0 & 0 \\
\hline Jumlah & 20 & 5 & 1 & 1 \\
\hline
\end{tabular}

3. Kalikan Semua Hasil Variable Puas dan Tidak Puas Langkah selanjutnya adalah mengalikan semua hasil variable puas dan tidak puas dengan menggunakan data uji. Berikut adalah data uji yang digunakan terdapat pada tabel 9 .

Tabel 9. Data Uji

\begin{tabular}{|c|c|c|c|c|c|c|c|c|}
\hline Alt & $\mathbf{A}$ & B & C & D & $\mathbf{E}$ & $\mathbf{F}$ & $\mathbf{G}$ & Tanggapan \\
\hline A26 & Dewasal & Wiraswasta & BR & B & B & B & B & $?$ \\
\hline A27 & Dewasa & Peg Swasta & $\mathrm{CL}$ & SB & SB & SB & $\mathrm{C}$ & $?$ \\
\hline A28 & Dewasa & Peg Swasta & $\mathrm{BR}$ & SB & $\mathrm{B}$ & $\mathrm{B}$ & $\mathrm{C}$ & $?$ \\
\hline A29 & Dewasa & Wiraswasta & $\mathrm{L}$ & SB & $\mathrm{B}$ & SB & SB & $?$ \\
\hline A30 & Dewasa & Peg Swasta & $\mathrm{BR}$ & SB & $\mathrm{B}$ & SB & $\mathrm{B}$ & $?$ \\
\hline A31 & Dewasa & Peg Swasta & $\mathrm{BR}$ & SB & SB & SB & B & $?$ \\
\hline A32 & Remaja & Pelajar & $\mathrm{BR}$ & SB & $\mathrm{B}$ & SB & SB & $?$ \\
\hline A33 & Dewasa & Peg BUMN & $\mathrm{CL}$ & SB & SB & SB & $\mathrm{B}$ & $?$ \\
\hline A34 & Dewasa & Peg BUMN & $\mathrm{L}$ & SB & SB & SB & SB & $?$ \\
\hline A35 & Dewasa & Peg Swasta & BR & SB & $\mathrm{B}$ & $\mathrm{B}$ & $\mathrm{C}$ & $?$ \\
\hline A36 & Remaja & Pelajar & $\mathrm{BR}$ & SB & $\mathrm{B}$ & $\mathrm{B}$ & $\mathrm{B}$ & $?$ \\
\hline A37 & Dewasa & Peg Swasta & $\mathrm{CL}$ & $\mathrm{B}$ & $\mathrm{B}$ & $\mathrm{B}$ & B & $?$ \\
\hline A38 & Dewasal & Wiraswasta & $\mathrm{BR}$ & B & $\mathrm{B}$ & $\mathrm{B}$ & $\mathrm{B}$ & $?$ \\
\hline A39 & Dewasa & Wiraswasta & CL & $\mathrm{B}$ & $\mathrm{B}$ & $\mathrm{B}$ & B & $?$ \\
\hline A40 & Tua & Peg BUMN & $\mathrm{L}$ & SB & SB & SB & B & $?$ \\
\hline A41 & Dewasa & Peg BUMN & CL & SB & SB & SB & SB & $?$ \\
\hline A42 & Dewasa & PNS & $\mathrm{CL}$ & $\mathrm{C}$ & $\mathrm{B}$ & $\mathrm{C}$ & $\mathrm{B}$ & $?$ \\
\hline A43 & Dewasa & Peg Swasta & BR & $\mathrm{C}$ & B & $\mathrm{C}$ & $\mathrm{C}$ & $?$ \\
\hline
\end{tabular}




\begin{tabular}{|c|c|c|c|c|c|c|c|c|}
\hline Alt & A & B & C & D & E & F & G & Tanggapan \\
\hline A44 & Tua & Peg Swasta & CL & B & C & B & C & $?$ \\
\hline A45 & dewasa & Pelajar & BR & B & C & C & B & $?$ \\
\hline A46 & Remaja & Pelajar & BR & B & C & B & C & $?$ \\
\hline A47 & Dewasa & Peg Swasta & BR & C & C & C & C & $?$ \\
\hline A48 & Dewasa & Pelajar & BR & C & B & C & B & $?$ \\
\hline A49 & Remaja & Pelajar & CL & B & SB & B & SB & $?$ \\
\hline A50 & Tua & Peg BUMN & L & SB & B & SB & B & $?$ \\
\hline
\end{tabular}

Keterangan :

A: Usia

B: Pekerjaan

C: Lama Menjadi Nasabah

D: Tangible

E: Reliability

F: Assurance

$\mathrm{G}$ : Responsiveness

Hasil belum diketahui klasifikasinya karena variabel tersebut merupakan hasil prediksi dari data yang dihitung dari setiap variabel. Berikut adalah proses perhitungannya :

$\mathrm{P}($ Dewasa \Puas $) \times \mathrm{P}($ Wiraswasta $\backslash$ Puas $) \times \mathrm{P}(\mathrm{BR} \backslash \mathrm{Puas}) \times \mathrm{P}(\mathrm{B} \backslash \mathrm{Puas}) \times \mathrm{P}(\mathrm{B} \backslash$ Puas $) \times P(B \backslash$ Puas $) \times P(B \backslash$ Puas $) \times P(P u a s)$

$=\frac{7}{20} \times \frac{3}{20} \times \frac{5}{20} \times \frac{17}{20} \times \frac{11}{20} \times \frac{13}{20} \times \frac{9}{20} \times \frac{20}{25}$

$=0.35 \times 0.15 \times 0.25 \times 0.85 \times 0.55 \times 0.65 \times 0.45 \times 0.80$

$=0.0014358093750$

$\mathrm{P}($ Dewasa \Tidak Puas) x P(Wiraswasta \Tidak Puas) x P(BR \Tidak Puas) x P(B $\backslash$ Tidak Puas) $\mathrm{x}$ P(B \Tidak Puas $)$ x P(B \Tidak Puas $) \times \mathrm{P}(\mathrm{B} \backslash$ Tidak Puas $) \mathrm{x}$ P(Tidak Puas)

$=\frac{3}{5} \times \frac{3}{5} \times \frac{0}{5} \times \frac{4}{5} \times \frac{3}{5} \times \frac{0}{5} \times \frac{0}{5} \times \frac{5}{25}$

$=0.60 \times 0.60 \times 0.00 \times 0.80 \times 0.60 \times 0.00 \times 0.00 \times 0.20$

$=0.00$

4. Bandingkan Hasil Class Puas \& Tidak Puas

Dari hasil perhitungan tersebut, bandingkan nilai probabilitas antara kelas (P|Puas) dan kelas (P|Tidak Puas) nilai probabilitas tertinggi ada pada kelas (P|Puas) sehingga dapat disimpulkan bahwa tanggapan nasabah tersebut masuk dalam klasifikasi "Puas"

\subsection{Pengujian Validasi dan Akurasi Algoritma Naïve Bayes}

Dari nilai probabilitas di atas akan diuji data sebanyak 25 data dan diselesaikan dengan menggunakan tools rapidminer sehingga dihasilkan hasil klasifikasi seperti pada gambar 1 berikut : 


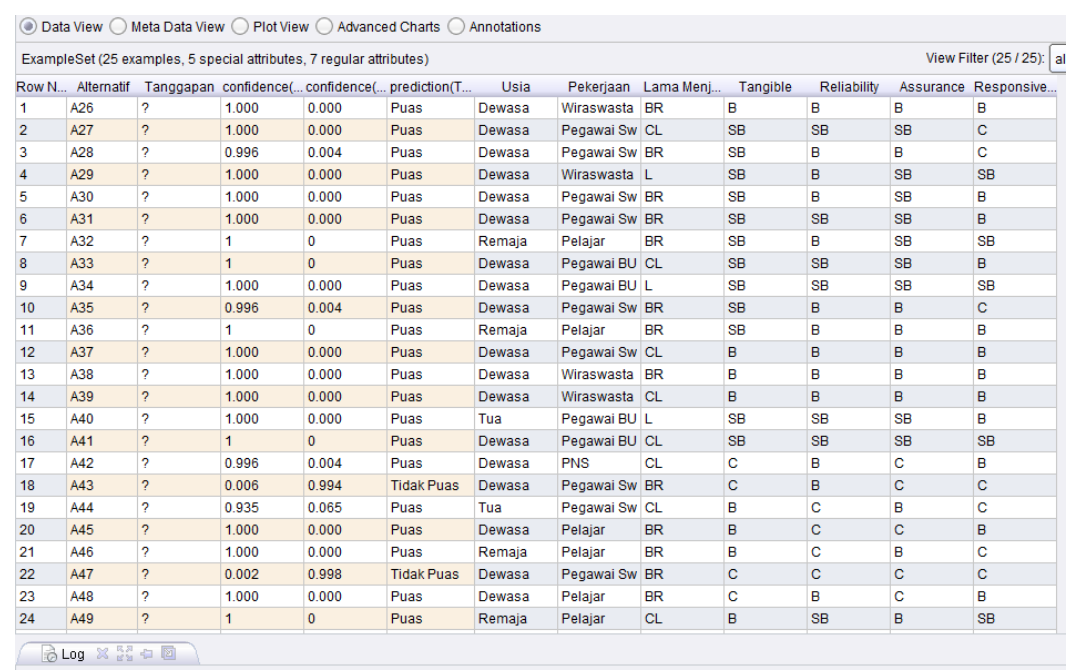

Gambar 1. Pembuktian Menggunakan Tools Rapid Miner

Pada gambar 1 dapat dilihat bahwa hasil dari perhitungan manual adalah sama dengan hasil perhitungan menggunakan tools rapidminer

Dalam melakukan validasi data terdapat hal-hal yang harus diperhatikan diantaranya : perhitungan manual algoritma harus telah menampilkan hasil akhir berupa pohon keputusan, serta data yang digunakan haruslah data yang valid dan sama dengan yang dipakai pada tools. Hasil pengujian Model Algoritma Naive Bayes Classfier ditunjukan pada gambar 2 berikut:

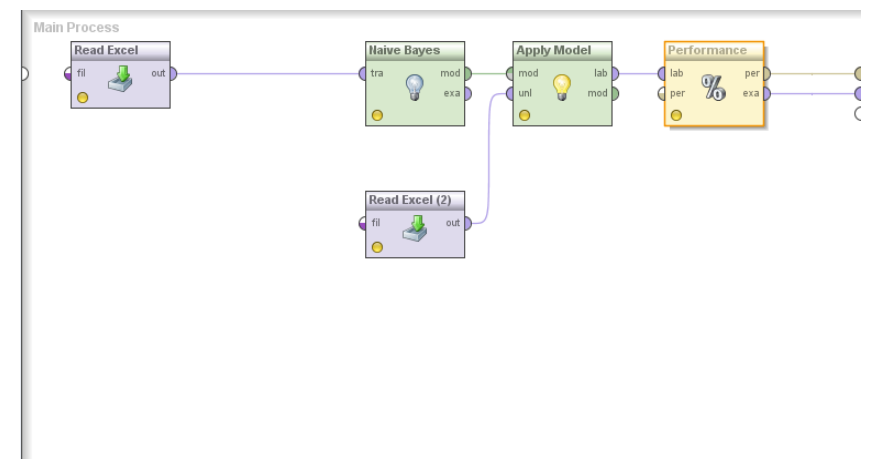

Penjelasan gambar 2 :

Gambar 2. Desain Klasifikasi Training dan Testing

1. Operator apply model digunakan untuk memprediksi dan menerapkan model dari data training.

2. Performance digunakan untuk mengetes hasil dari data training, performance memberikan nilai accuracy

Running dari desain adalah

1. Accuracy

Akurasi adalah ukuran dari seberapa baik model mengkorelasikan antara hasil dengan atribut dalam data yang telah disediakan 


\begin{tabular}{|c|c|c|c|}
\hline \multicolumn{2}{|c|}{ (1) Multiclass Classification Performance $\bigcirc$ Annotations } & & $x \in \underbrace{\circ}$ \\
\hline \multicolumn{4}{|c|}{ ○ Table View OPlot View } \\
\hline \multicolumn{4}{|l|}{ accuracy: 88.00\% } \\
\hline & true Puas & true Tidak Puas & class precision \\
\hline pred. Puas & 20 & 3 & $86.96 \%$ \\
\hline pred. Tidak Puas & 0 & 2 & $100.00 \%$ \\
\hline class recall & $100.00 \%$ & $40.00 \%$ & \\
\hline
\end{tabular}

Gambar 3. Nilai Accuracy Performance

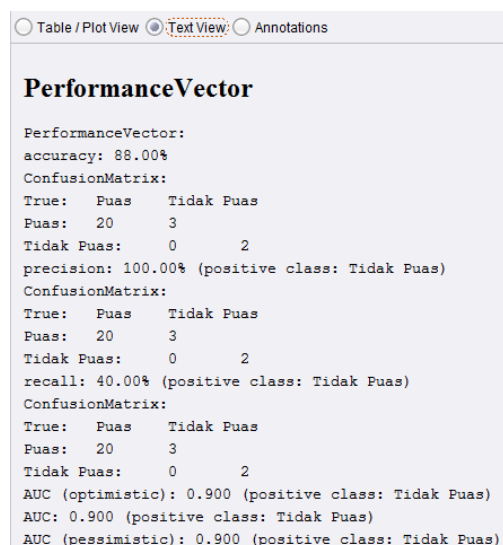

Gambar 4. Detail Performance Vector

Berdasarkan gambar yang telah dijelaskan di atas, maka dapat diketahui bahwa pengujian data yang dilakukan dengan menggunakan apply model dan \%Performance diperoleh nilai akurasi 88\% dapat dikategorikan model algoritma Naïve Bayes ini adalah execellent.

\section{KESIMPULAN}

Penerapan Datamining dengan menggunakan algoritma naive bayes pada kualitas pelayanan terhadap kepuasan nasabah Bank BTN KC Pematangsiantar dapat diterapkan. Sumber data yang digunakan pada penelitian ini adalah data yang diperoleh langsung dari nasabah. Jumlah data yang data uji sebanyak 25 nasabah dengan menggunakan dua kelas. Dari hasil perhitungan Algoritma Naive Bayes diperoleh klasifikasi dengan kelas Puas sebanyak 20 nasabah dan kelas Tidak Puas sebanyak 5 nasabah.

Pengujian data pada Rapidminer 5.3 menggunakan naive bayes dapat menampilkan dua kelas dari hasil klasifikasi dengan tingkat akurasi sebesar 88.00\%. dan dapat dikategorikan execellent .

\section{DAFTAR PUSTAKA}

[1] T. P. Kiling, "PERAN KOMUNIKASI FRONTLINER DALAM MENINGKATKAN PELAYANAN DI PT BNI (PERSERO) TBK KANTOR LAYANAN KAWANGKOAN," e- journal “Acta Diurna," vol. V, no. 3, 2016.

[2] M. G. Sadewo, A. P. Windarto, and D. Hartama, "Penerapan Datamining Pada Populasi Daging Ayam Ras Pedaging Di Indonesia Berdasarkan Provinsi Menggunakan K-Means," InfoTekJar (Jurnal Nasional Informatika dan Teknologi Jaringan), vol. 2, no. 1, pp. 60-67, 2017.

[3] Bustami, "Penerapan Algoritma Naive Bayes untuk Mengklasifikasi Data Nasabah Asuransi," Jurnal Penelitian Teknik Informatika Universitas Ahmad Dahlan (TECHSI), no. 1, pp. 128-146, 
2014.

[4] W. Muslehatin, M. Ibnu, and Mustakim, "Penerapan Naïve Bayes Classification untuk Klasifikasi Tingkat Kemungkinan Obesitas Mahasiswa Sistem Informasi UIN Suska Riau," Seminar Nasional Teknologi Informasi, Komunikasi dan Industri (SNTIKI), pp. 18-19, 2017.

[5] A. Saleh, "Implementasi Metode Klasifikasi Naïve Bayes Dalam Memprediksi Besarnya Penggunaan Listrik Rumah Tangga," no. January 2015, 2016.

[6] I. Parlina, A. P. Windarto, A. Wanto, and M. R. Lubis, "Memanfaatkan Algoritma K-Means dalam Menentukan Pegawai yang Layak Mengikuti Asessment Center untuk Clustering Program SDP," CESS (Journal of Computer Engineering System and Science), vol. 3, no. 1, pp. 87-93, 2018.

[7] R. W. Sari, A. Wanto, and A. P. Windarto, "Implementasi Rapidminer dengan Metode KMeans (Study Kasus: Imunisasi Campak pada Balita Berdasarkan Provinsi)," KOMIK (Konferensi Nasional Teknologi Informasi dan Komputer), vol. 2, no. 1, pp. 224-230, 2018.

[8] S. Sudirman, A. P. Windarto, and A. Wanto, "Data Mining Tools | RapidMiner: K-Means Method on Clustering of Rice Crops by Province as Efforts to Stabilize Food Crops In Indonesia," IOP Conference Series: Materials Science and Engineering, vol. 420, no. 12089, pp. 1-8, 2018.

[9] A. P. Windarto, "Implementation of Data Mining on Rice Imports by Major Country of Origin Using Algorithm Using K-Means Clustering Method," International Journal of artificial intelligence research, vol. 1, no. 2, pp. 26-33, 2017.

[10] A. P. Windarto, "Penerapan Data Mining Pada Ekspor Buah-Buahan Menurut Negara Tujuan Menggunakan K-Means Clustering,” Techno.COM, vol. 16, no. 4, pp. 348-357, 2017.

[11] M. G. Sadewo, A. P. Windarto, and A. Wanto, "Penerapan Algoritma Clustering dalam Mengelompokkan Banyaknya Desa/Kelurahan Menurut Upaya Antisipasi/ Mitigasi Bencana Alam Menurut Provinsi dengan K-Means," KOMIK (Konferensi Nasional Teknologi Informasi dan Komputer), vol. 2, no. 1, pp. 311-319, 2018.

[12] A. Saleh, "PENERAPAN DATA MINING DENGAN METODE KLASIFIKASI NAÏVE BAYES UNTUK MEMPREDIKSI KELULUSAN MAHASISWA DALAM MENGIKUTI ENGLISH PROFICIENCY TEST ( Studi Kasus : Universitas Potensi Utama ) PENERAPAN DATA MINING DENGAN METODE KLASIFIKASI NAÏVE MENGIKUTI ENGLISH ," no. February 2015, 2016. 